Jurnal Teknologi Kimia Unimal $7: 1$ (November 2018) 154 - 154

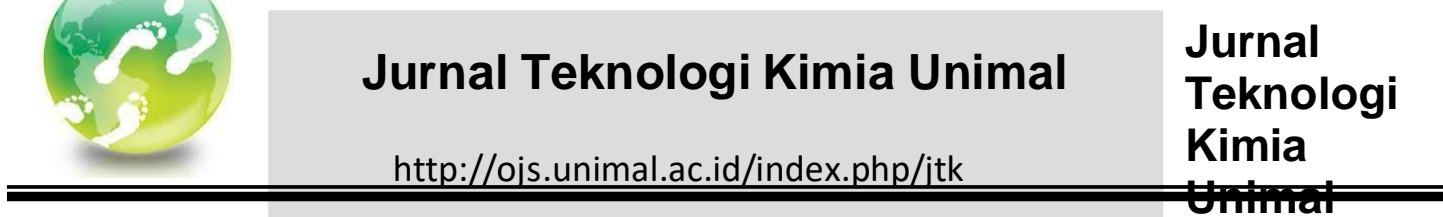

\title{
Optimasi Pengendalian Flow Control DEA Absorber Menggunakan Proportional Integral Derivative (PID) Control Dengan Metode Respon Surface Methodology (RSM)
}

Muhammad, Azizi Maharani, Maulinda Leni Jurusan Teknik Kimia, Fakultas Teknik, Universitas Malikussaleh Kampus Utama Jalan Batam, Bukit Indah, Lhokseumawe - 24355 e-mail: mhdtk@unimal.ac.id

\section{Abstrak}

Absorbsi merupakan salah satu cara untuk memisahkan atau mengurangi suatu konsituen dalam fasa gas dengan menggunakan solvent atau penyerap tertentu secara relative yang dapat melarutkan atau menyerap konsituen yang diinginkan. Tujuan dari penelitian ini yaitu untuk menentukan nilai $\mathrm{Kc}$, Ti dan Td terbaik pada kontrol PID DEA absorber Perta Arun Gas. Sistem kontrol Proportional, Integral and Derivative (PID) merupakan controller untuk menentukan presisi suatu sistem instrumentasi dengan karakteristik adanya umpan balik pada sistem tersebut (Feed Back). Response Surface Methodology (RSM) atau metode permukaan respon adalah sekumpulan metode-metode matematika dan statistika yang digunakan dalam pemodelan dan analisis, yang bertujuan untuk melihat pengaruh beberapa variabel kuantitatif terhadap suatu variabel respon dan untuk mengoptimalkan variabel respon tersebut. Adapun metodologi dari penelitian ini adalah membuat model steady state DEA absorber menjadi model dynamic, lalu membuat model kontrol PID, setelah itu melakukan tuning terhadap kontrol PID dan melakukan pengujian terhadap kontrol $P I D$ dengan melakukan gangguan pada $P V$. Hasil dari pengaplikasian sistem kontrol PID maka mendapatkan waktu tercepat dengan nilai $\mathrm{Kc}=$ $\mathrm{Kc}=0,1, \mathrm{Ti}=0,01$, dan $\mathrm{Td}=0,00001$ dengan waktu 0,510 menit.

Kata kunci: Absorbsi, PID, Present Value, Controller

\section{Pendahuluan}

Pada pabrik pengolahan gas alam, absorbsi adalah salah satu unit operasi yang digunakan untuk pemurnian gas (gas treating) bertujuan untuk memisahkan feed gas dari gas impurities $\left(\mathrm{CO}_{2}, \mathrm{H}_{2} \mathrm{~S}, \mathrm{Hg}\right.$ dan hidrokarbon berat) yang dapat meyebabkan korosivitas pipa - pipa pabrik. Pada proses yang dilakukan dibutuhkan pengendalian atau controller dan salah satu permasalahan yang sering terjadi pada hampir semua pengendalian (controller) termasuk pengendalian laju alir (flow rate). Dalam hal ini kesalahan pada pengendalian flow rate larutan penyerap pada operasi absorbsi mengakibatkan penyerapan pada feed gas di proses pemurnian gas (gas treating) tidak sesuai dengan yang diinginkan. 
Dalam penelitian ini masalah yang akan dibahas adalah optimasi dari flow control yang ada pada DEA absorber menggunakan tuning parameter Kc, Ti dan Td yang terbaik untuk respon waktu tercepat dalam menanggulangi gangguan pada present value (PV).

\section{Tinjauan Pustaka}

\subsection{PID (Proportional, integral dan derivative)}

PID merupakan kombinasi dari proportional, integral dan derivative model control adalah PID controller, ada banyak variasi dari PID controller. Berikut adalah variasi yang paling sederhana, yaitu :

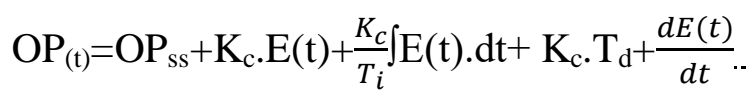

Control PID (Proportional Integral Derivative) adalah salah satu sistem pengendalian proses pada industri pabrik. Pada pengendalian proses menggunakan PID membantu pekerjaan operator dalam menjalankan dan mengamati proses pabrik pabrik (Xue, 2007).

Control PID adalah jenis pengendali yang sering digunakan di pabrik. Selain sistem pengendali PID ini mudah digabungkan dengan metode pengendalian yang lain seperti Fuzzy and Robust, sehingga menjadi sistem pengendali yang baik (Abdussamad, 2009).

Blok diagram suatu sistem loop tertutup dapat dilihat Gambar 1.

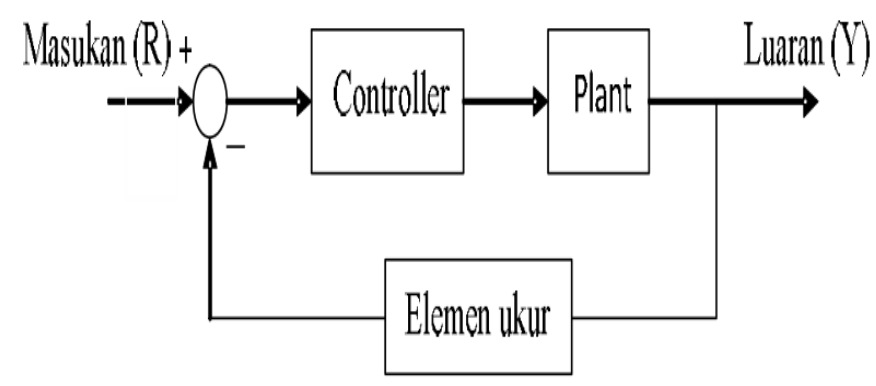

Gambar 1 Blok diagram suatu sistem loop tertutup

Tabel 1 Parameter tuning PID

\begin{tabular}{|l|l|l|l|}
\hline Sistem & $\mathrm{K}_{\mathrm{c}}$ & $\mathrm{T}_{\mathrm{i}}$ & $\mathrm{T}_{\mathrm{d}}$ \\
\hline Laju Alir & 0,1 & 0,2 & 0 \\
\hline Tekanan & 2 & 2 & 0 \\
\hline Temperatur & 1 & 20 & 0 \\
\hline Level & 2 & 10 & 0 \\
\hline
\end{tabular}

Sumber : Tabel 1 Dissenger, 2013 
Tabel 2 Lebar Waktu Cuplik Yang Umum Digunakan Untuk Beberapa Jenis Variabel Proses

\begin{tabular}{|l|l|l|}
\hline No & \multicolumn{1}{|c|}{ Jenis Variabel } & \multicolumn{1}{|c|}{$\begin{array}{c}\text { Waktu Cuplik }-\mathrm{T}_{\mathrm{c}} \\
\text { (detik) }\end{array}$} \\
\hline 1 & Aliran (flow) & $1-3$ \\
\hline 2 & Level & $5-10$ \\
\hline 3 & Tekanan & $1-5$ \\
\hline 4 & Temperatur & $10-20$ \\
\hline
\end{tabular}

Sumber : Tabel 2 Iwan Setiawan, 2008

Namun, pengendalian PID (Proportional Integral Derivative) mempunyai kelemahan, diantaranya adalah pengendali PID tidak dirancang untuk menyelesaikan sistem nonlinear dengan banyak ketidakpastian (uncertainties).

Tabel 1 dan Tabel 2 menunjukkan parameter dalam melakukan penyetelan (tuning) pada PID (Julie Levine, 2013).

\subsection{Parameter Pengontrol PID dan Metode Respon Surface Methodology}

Parameter pengontrol PID selalu didasari atas tinjauan terhadap karakteristik yang diatur (plant). Dengan demikian berapapun rumitnya suatu plant, perilaku plant tersebut harus diketahui terlebih dahulu sebelum penalaan parameter PID itu dilakukan. Karena penyusunan model matematik plant tidak mudah, maka dikembangkan suatu metode eksperimental. Metode ini didasarkan pada reaksi plant yang dikenai suatu perubahan. Dengan menggunakan metode itu model matematik perilaku plant tidak diperlukan lagi, karena dengan menggunakan data yang berupa kurva keluaran, penalaan pengontrol PID telah dapat dilakukan. Penalaan bertujuan untuk mendapatkan kinerja sistem sesuai spesifikasi perancangan.

Suatu sistem pengendalian terdapat proses tuning atau penyetelan alat agar didapatkan sistem dengan hasil respon yang stabil. Berbagai macam metode tuning telah ditemukan. Salah satunya adalah dengan menggunakan Respon Surface Methodology (RSM). Response Surface Methodology (RSM) atau metode permukaan respon adalah sekumpulan metode-metode matematika dan statistika yang digunakan dalam pemodelan dan analisis, yang bertujuan untuk melihat pengaruh beberapa variabel kuantitatif terhadap suatu variabel respon dan untuk mengoptimalkan variabel respon tersebut. Sebagai contoh, akan dicari level-level dari suhu $\left(x_{1}\right)$ dan tekanan $\left(x_{2}\right)$ yang dapat mengoptimalkan suatu hasil produksi $(y)$. Hubungan variabel-variabel tersebut dapat dituliskan dalam sebah persamaan sebagai berikut : 
Dimana $\varepsilon$ merupakan error pengamatan pada respon $y$. Jika nilai harapan respon dituliskan $E y=(x 1+x 2)=\eta$, maka $\eta=f(x 1+x 2)$ merepresentasikan sebuah permukaan yang disebut permukaan respon. Pada umumnya, permukaan respon digambarkan dengan sebuah grafik, seperti yang tampak pada Gambar 2.3. Untuk membantu visualisasi dari bentuk permukaan plot, sering digunakan kontur dari permukaan respon, seperti yang terlihat pada Gambar 2.4. Pada kontur tersebut, garis respon yang konstan berada pada permukaan datar $\left(x_{1}, x_{2}\right)$, sedangkan garis respon yang lain berada pada permukaan lengkung di atasnya.

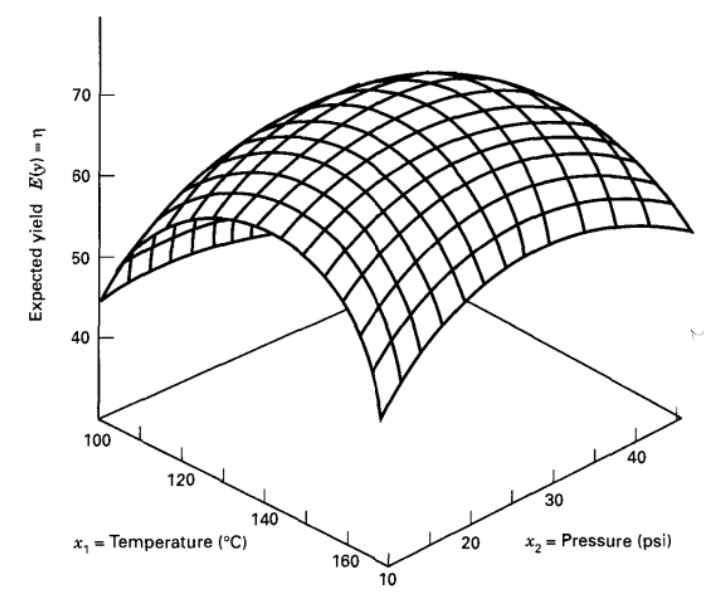

Gambar 2 Ilustrasi Plot Permukaan Respon

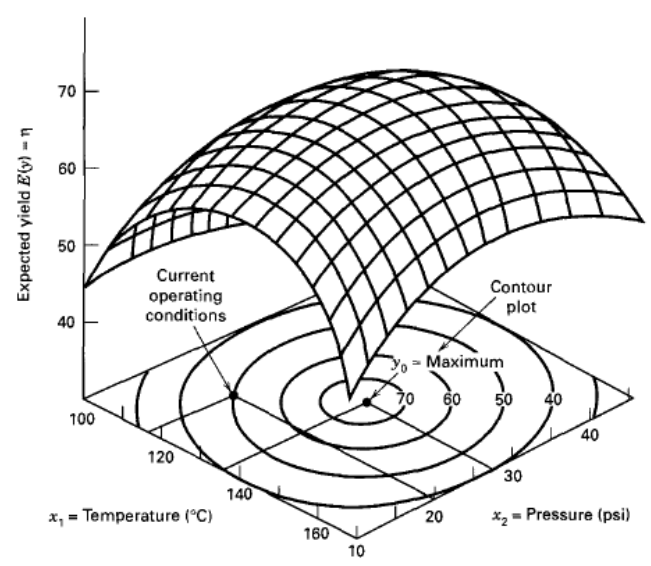

Gambar 3 Ilustrasi Plot Kontur Response Surface

Permasalahan umum pada metode permukaan respon adalah bentuk hubungan antara variabel respon dengan variabel independen tidak diketahui. Oleh karena itu, langkah pertama dalam metode permukaan respon adalah mencari bentuk hubungan antara respon dengan beberapa variabel independen melalui pendekatan yang sesuai. Bentuk hubungan linier merupakan bentuk hubungan yang dicobakan pertama kali karena merupakan bentuk hubungan yang paling sederhana (low-order polynomial). Jika 
Muhammad dkk./ Jurnal Teknologi Kimia Unimal 7 : 2 (November 2018) 152 - 162

ternyata bentuk hubungan antara respon dengan variabel independen adalah fungsi linier, pendekatan fungsinya disebut first-order model, seperti yang ditunjukkan dalam persamaan 3 .

$$
y=\beta_{0}+\beta_{1} x_{1}+\beta_{2} x_{2}+\cdots \cdots+\beta_{k} x_{k}+\varepsilon_{i}
$$

Jika bentuk hubungannya merupakan kuadrat, maka untuk pendekatan fungsinya digunakan derajat polinomial yang lebih tinggi yaitu second-order model dengan menggunakan persamaan 2.6 berikut:

$$
y=\beta_{0+} \sum_{i=1}^{k} \beta_{i} x_{i}+\sum_{i=1}^{k} \beta_{i i} x_{i}^{2}+\ldots . .+\sum_{i<j} \sum \beta_{i f} x_{i} x_{f}+\varepsilon
$$

Hampir semua permasalahan dalam metode permukaan respon menggunakan salah satu atau kedua model diatas. Setelah diperoleh bentuk hubungan yang paling sesuai, langkah selanjutnya adalah mengoptimalisasi hubungan tersebut. Jika permukaan yang paling sesuai dicari melalui pendekatan yang cukup, maka hasil analisis ini akan mendekati fungsi yang sebenarnya. Secara garis besar, langkah-langkah dalam metode permukaan respon adalah merancang percobaan, membuat model dan melakukan optimalisasi.

\section{Bahan dan Metode}

Penelitian ini mengkaji respon dari controller flow rate masukan DEA pada absorber dalam menghadapi gangguan di dalam proses industri dengan menggunakan controller PID.

\subsection{Variabel - variabel dalam Penelitian}

Variabel - variabel yang digunakan dalam penelitian pada Tabel 3.1 Variabel variabel dalam penelitian.

\begin{tabular}{|c|c|c|}
\hline Variabel Tetap & Variabel Bebas & Variabel Terikat \\
\hline $\begin{array}{l}\text { 1. Tekanan } \\
\text { Diethanolamine } \\
\text { (DEA) } 49,46 \text { bar } \\
\text { 2. Temperatur } \\
\text { Diethanolamine } \\
\text { (DEA) } 58,2^{\circ} \mathrm{C} \\
\text { 3. Tekanan feed gas } \\
49,42 \text { bar } \\
\text { 4. Temperatur feed gas } \\
40^{\circ} \mathrm{C} \\
\text { 5. Komposisi feed gas } \\
\text { 6. Setpoint } 104,5 \mathrm{~kg} / \mathrm{h}\end{array}$ & $\begin{array}{llr}\text { 1. } & \mathrm{K}_{\mathrm{C}} \text { dengan nilai } \\
0,1,0,15 \text { dan } 0,2 \\
\text { 2. } \mathrm{Ti} \text { dengan nilai } \\
0,01,0,02 \text { dan } \\
0,03 \\
\text { 3. } \mathrm{Td} \text { dengan nilai } \\
0,0,00001 \text { dan } \\
0,00002\end{array}$ & $\begin{array}{l}\text { 1. Waktu tercepat } \\
\text { mencapai Setpoint }\end{array}$ \\
\hline
\end{tabular}

Tabel 3 Variabel - variabel dalam penelitian 


\section{Hasil dan Pembahasan}

\subsection{Hasil}

Tabel 4 Hasil Pengujian Kontrol PID dari Respon Surface Methodology (RSM)

\begin{tabular}{|c|c|c|c|c|c|}
\hline RUN & $\mathrm{Kc}$ & $\begin{array}{c}\mathrm{Ti} \\
\text { (menit) }\end{array}$ & $\begin{array}{c}\text { Td } \\
\text { (menit) }\end{array}$ & $\begin{array}{l}\text { Waktu } \\
\text { mencapai } \\
\text { setpoint } \\
\text { (menit) }\end{array}$ & $\begin{array}{c}\text { Bukaan } \\
\text { valve } \\
(\%)\end{array}$ \\
\hline 1 & 0,1 & 0,03 & 0,00001 & 1,057 & 17,05 \\
\hline 2 & 0,15 & 0,02 & 0,00001 & 0,989 & 17,05 \\
\hline 3 & 0,1 & 0,01 & 0,00001 & 0,510 & 17,05 \\
\hline 4 & 0,2 & 0,03 & 0,00001 & 1,083 & 17,05 \\
\hline 5 & 0,15 & 0,01 & 0 & 0,587 & 17,05 \\
\hline 6 & 0,1 & 0,02 & 0,00002 & 1,114 & 17,08 \\
\hline 7 & 0,15 & 0,01 & 0,00002 & 0,981 & 17,06 \\
\hline 8 & 0,2 & 0,02 & 0,00002 & 0,832 & 17,05 \\
\hline 9 & 0,1 & 0,02 & 0 & 1,511 & 17,05 \\
\hline 10 & 0,15 & 0,03 & 0,00002 & 1,114 & 17,06 \\
\hline 11 & 0,2 & 0,01 & 0,00001 & 0,516 & 17,05 \\
\hline 12 & 0,15 & 0,03 & 0 & 1,385 & 17,05 \\
\hline 13 & 0,2 & 0,02 & 0 & 0,875 & 17,05 \\
\hline
\end{tabular}

Tabel 5 Pengujian Gangguan Kontrol PID dengan Nilai tuning parameter optimum yang didapat pada hasil Respon Surface Methodology $(\mathrm{RSM}) \mathrm{Kc}=0,1, \mathrm{Ti}=0,01$ dan

$\mathrm{Td}=0,00001$

\begin{tabular}{|c|c|c|c|c|c|}
\hline $\begin{array}{l}\text { Flow Rate } \\
\text { DEA }(\mathrm{kg} / \mathrm{h})\end{array}$ & Kc & $\mathrm{Ti}$ & $\mathrm{Td}$ & $\begin{array}{l}\text { Waktu } \\
\text { (Menit) }\end{array}$ & $\begin{array}{c}\text { Bukaan } \\
\text { Valve } \\
(\%)\end{array}$ \\
\hline $112,3-104,5$ & \multirow{3}{*}{0,1} & \multirow{3}{*}{0,01} & \multirow{3}{*}{0,00001} & 0,070 & 14,08 \\
\hline $104,5-105,3$ & & & & 0,320 & 17,08 \\
\hline $104,5-102,2$ & & & & 0,695 & 90,14 \\
\hline
\end{tabular}




\begin{tabular}{|c|l|l|l|c|c|}
\hline $112,3-104,5$ & & & & 0,650 & 14,50 \\
\hline Rata-rata & \multicolumn{2}{|l}{0,878} & 35,23 \\
\hline
\end{tabular}

\subsection{Analisa Varian (ANOVA)}

\subsubsection{Waktu Tercepat $\left(Y_{1}\right)$}

Waktu respon pada tuning Kc, Ti dan Td yang terdapat pada Respon Surface Methodology (RSM) mendapatkan analisa ANOVA. Analisa varian untuk waktu tercepat ditampilkan pada Tabel 6.

Tabel 6 Analisa Varian (ANOVA) Waktu Respon

\begin{tabular}{|c|c|c|c|c|c|c|}
\hline Sumber & $\begin{array}{c}\text { Jumlah } \\
\text { Kuadran }\end{array}$ & DF & $\begin{array}{c}\text { Mean } \\
\text { Square }\end{array}$ & $\begin{array}{c}F \\
\text { Value }\end{array}$ & $\begin{array}{c}\text { Prob }> \\
\text { F }\end{array}$ & Ket \\
\hline Model & 0,96 & 9 & 0,11 & 4,79 & 0,0255 & Signifikan \\
\hline A-Kc & 0,098 & 1 & 0,098 & 4,39 & 0,0745 & \\
\hline B-Ti & 0,52 & 1 & 0,52 & 23,36 & 0,0019 & \\
\hline C-Td & 0,013 & 1 & 0,013 & 0,56 & 0,4781 & \\
\hline AB & 0,00001 & 1 & 0,00001 & 0,0045 & 0,9486 & \\
\hline AC & 0,031 & 1 & 0,031 & 1,40 & 0,2753 & \\
\hline BC & 0,11 & 1 & 0,11 & 4,94 & 0,0616 & \\
\hline $\mathrm{A}^{2}$ & 0,018 & 1 & 0,018 & 0,81 & 0,3979 & \\
\hline $\mathrm{B}^{2}$ & 0,073 & 1 & 0,073 & 3,27 & 0,1134 & \\
\hline $\mathrm{C}^{2}$ & 0,11 & 1 & 0,11 & 4,80 & 0,0647 & \\
\hline Residual & 0,16 & 7 & 0,22 & & & \\
\hline Lack of Fit & 0,16 & 3 & 0,052 & & & \\
\hline Pure Error & 0,0 & 4 & 0 & & & \\
\hline Cor Total & 1,12 & 16 & & & & \\
\hline
\end{tabular}

Keterangan : Mean Square = Jumlah kuadrat rata-rata

$$
\begin{array}{ll}
\mathrm{A} & =\mathrm{Kc} \\
\mathrm{B} & =\mathrm{Ti} \\
\mathrm{C} & =\mathrm{Td} \\
\mathrm{A}^{2} & =\text { Hubungan antara } \mathrm{Kc} \text { dan } \mathrm{Kc} \\
\mathrm{B}^{2} & =\text { Hubungan antara Ti dan } \mathrm{Ti} \\
\mathrm{C}^{2} & =\text { Hubungan antara Td dan } \mathrm{Td}
\end{array}
$$


Tabel 6 menunjukkan ANOVA waktu tercepat dengan Design Expert 7.0.0. model dapat dinyatakan memiliki pengaruh yang signifikan karena memiliki nilai probalitas $<0,05$. Namun jika nilai $>0,05$ maka model yang ditunjukkan tidak signifikan.

Tabel 7 Menunjukkan Nilai Squared

\begin{tabular}{|c|c|c|c|}
\hline Std. Dev & 0,15 & $R$-Squared & 0,8603 \\
\hline Mean & 0,97 & Adj $R$-Squared & 0,6807 \\
\hline C.V.\% & 15,40 & Pred $R$-Squared & $-1,2352$ \\
\hline PRESS & 2,51 & Adeq $R$-Squared & 9,223 \\
\hline
\end{tabular}

Sebuah model dapat dikategorikan sebagai model yang sesuai apabila model tersebut memiliki koefisien korelasi $\mathrm{R}^{2}>0,85$. Berikut ini adalah persamaan coded factor, yaitu :

Waktu tercepat $=+0,99-0,11 \mathrm{~A}+0,26 \mathrm{~B}-0,040 \mathrm{C}+0,005 \mathrm{AB}+0,088 \mathrm{AC}-0,17 \mathrm{BC}$

$$
-0,066 \mathrm{~A}^{2}-0,13 \mathrm{~B}^{2}+0,16 \mathrm{C}^{2}
$$

Model grafik waktu tercepat dapat dilihat pada Gambar 4.

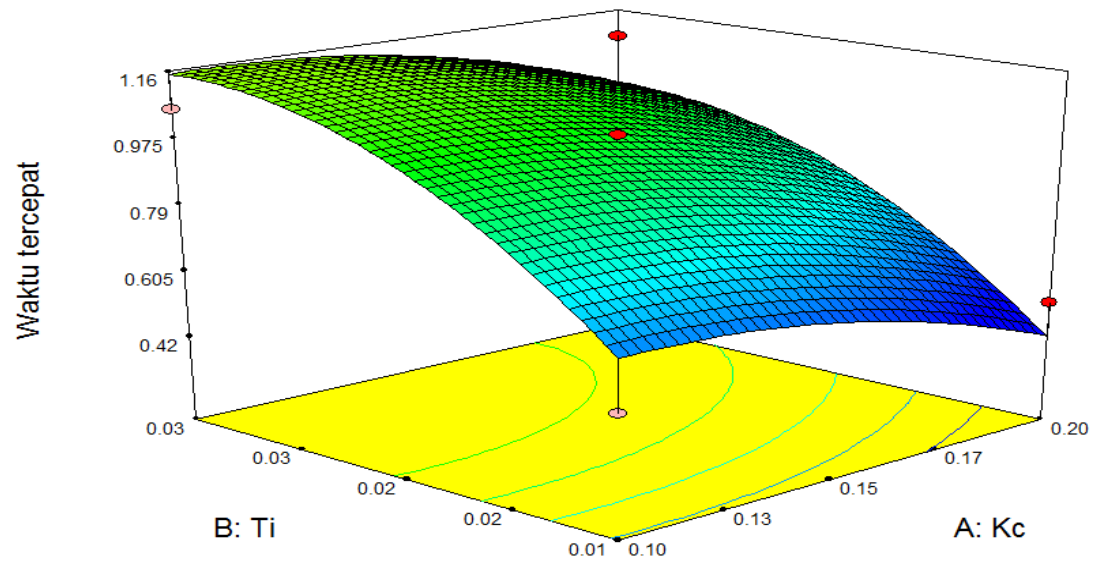

Gambar 4 Grafik respon waktu tercepat

\subsubsection{Pengujian Gangguan Kontrol PID dengan Tuning Parameter Kc, Ti dan Td Optimum}

Pada kontrol PID diperlukan pengujian yang bertujuan untuk mengetahui parameter tuning Kc, Ti dan Td berfungsi sebagai kendali yang baik pada kontrol yang digunakan. Karena itu diberi gangguan pada present value (PV).

\subsubsection{Pengujian Gangguan Kontrol PID dengan Nilai $\mathrm{Kc}=0,1, \mathrm{Ti}=0,01$ dan $\mathrm{Td}=$ 0,00001}


Pada penelitian ini nilai setpoint yang digunakan adalah $104,5 \mathrm{~kg} / \mathrm{h}$. Untuk batas maksimum yang mampu dicapai setelah diberikan gangguan terhadap present value (PV)-nya yaitu maksimum $112,3 \mathrm{~kg} / \mathrm{h}$ dan untuk batas minimumnya yaitu $74,5 \mathrm{~kg} / \mathrm{h}$. Nilai tuning yang digunakan adalah $\mathrm{Kc}=0,1, \mathrm{Ti}=0,01$ dan $\mathrm{Td} 0,00001$.

Data yang ada pada Tabel 7 menjadi bentuk grafik model PID seperti yang terlihat pada Gambar 5.

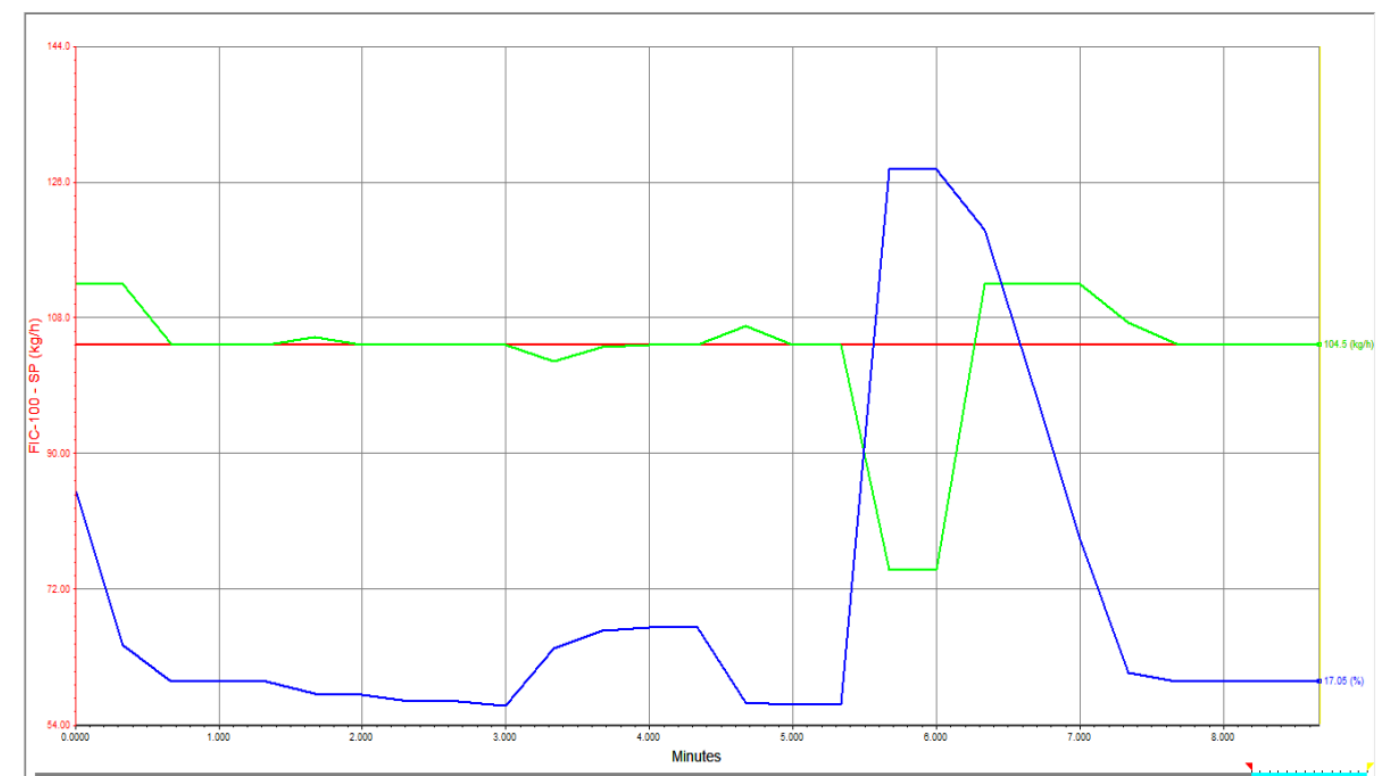

Gambar 5 Grafik PID pada gangguan present value (PV) pada tuning parameter $\mathrm{Kc}=0,1$, $\mathrm{Ti}=0,01$ dan $\mathrm{Td}=0,00001$

Keterangan Gambar: $\square$ Garis present value (PV), $\square$ Garis setpoint (SP), $\square$ Garis Bukaan Valve (OP)

\section{Kesimpulan}

Pengujian menggunakan nilai tuning $\mathrm{Kc}=0,1, \mathrm{Ti}=0,01$ dan $\mathrm{Td}=0,00001$. Menunjukkan hubungan grafik SP cenderung tetap dan grafik PV bergerak menyamakan nilai dengan SP dengan perubahan pada grafik PV berpengaruh pada persentase sinyal bukaan valve (OP). Flow rate DEA awal sebelum ada gangguan pada SP adalah 104,5 $\mathrm{kg} / \mathrm{h}$ dan PV diubah menjadi 102,2 kg/h mendapatkan waktu respon sebesar 0,590 menit dengan bukaan valve 22,42\%, setelah itu diganggu dengan dinaikkan nilai PV sebesar $106,8 \mathrm{~kg} / \mathrm{h}$ untuk mencapai SP kembali dibutuhkan waktu respon 0,325 menit dengan bukaan valve 13,83\%, dinaikkan besaran PV untuk mengganggu kendali kontrol sebesar $74,5 \mathrm{~kg} / \mathrm{h}$ didapatkan waktu respon sebesar 1,950 menit dengan bukaan valve 90,14\% dan gangguan terakhir diberikan sebesar $112,3 \mathrm{~kg}$ didapatkan waktu respon sebesar 0,650 menit dengan bukaan valve $14,50 \%$. 
Pada buka dan tutupnya valve dikendalikan oleh Flow Indicator Controller (FIC). Fungsi control valve adalah mengatur flow DEA yang masuk ke absorber. Semakin besar flow rate DEA yang diberikan semakin kecil bukaan valve yang dibuka, itu dikarenakan oleh flow rate DEA yang harus masuk sebesar $104,5 \mathrm{~kg} / \mathrm{h}$ dan jika bukaan valve yang dibuka terlalu besar maka flow rate DEA yang mengalir akan besar, begitu pun sebaliknya jika flow rate DEA sedikit bukaan valve yang terbuka akan besar.

Pada pengujian tuning parameter optimum yang didapat dari hasil Respon Surface Methodology $(\mathrm{RSM})$ tuning parameter $\mathrm{Kc}=0,1, \mathrm{Ti}=0,01$ dan $\mathrm{Td}=0,00001$ dengan waktu rata-rata dalam menghadapi gangguan present value (PV) sebesar 0,878 menit dan tuning parameter tersebut juga merupakan rekomendasi tuning untuk flow control (Levine, Technology, Dissinger, Management, \& Technology, 2013).

Pada tuning tersebut waktu yang diperlukan pada respon cepat dan itu dibutuhkan untuk flow control yang dipasangkan di absorber. Sehingga kelebihan dan kekurangan DEA untuk absorber dapat ditanggani dengan cepat dan kerugian yang disebabkan oleh gangguan dapat diperkecil.

\section{Daftar Pustaka}

Abdussamad, S. (2009). SIMULASI KENDALIAN FLOW CONTROL UNIT G . U . N . T TIPE 020 DENGAN PENGENDALI PID Abstrak.

Julie Levine, G. D. (2013). Jump Start: Aspen HYSYS ® Dynamics V8.

Levine, J., Technology, A., Dissinger, G., Management, P., \& Technology, A. (2013). Jump Start : Aspen HYSYS ${ }^{\circledR}$ Dynamics V8.

Xue, D. (2007). PID Controller Design. 
Muhammad dkk./ Jurnal Teknologi Kimia Unimal 7 : 2 (November 2018) 152 - 162 